\title{
Trends in Patient-Centered Care in South West Nigeria: A Holistic Assessment of the Nurses Perception of Primary Healthcare Practice
}

\author{
Adepeju M. Lateef ${ }^{1} \&$ Euphemia. M. Mhlongo ${ }^{1}$ \\ ${ }^{1}$ School of Nursing and Public Health, University of KwaZulu-Natal, Howard College, Durban, 4001, South \\ Africa \\ Correspondence: Adepeju M. Lateef, University of KwaZulu-Natal, School of Nursing and Public Health, Howard \\ College, Desmond Clarence Building 5th Floor, Durban, 4001, South Africa. Tel: 27-632-134-579. E-mail: \\ princessadepejuu@gmail.com
}

Received: November 20, 2019 Accepted: January 19, 2020 Online Published: April 14, 2020

doi:10.5539/gjhs.v12n6p73

URL: https://doi.org/10.5539/gjhs.v12n6p73

\section{Abstract}

Background: A key dimension of a quality healthcare to patients is patient-centered care approach which is increasingly gaining recognition worldwide. However, this concept is not fully implemented in practice.

Aim: The aim of this study is to provide outcomes from assessment of nurses' perceptions about patient-centered care and the current trends in Primary Health Care system in South West Nigeria.

Methods: This study employed a qualitative participatory action research study approach and conducted a semi-structured individual interview with thirty-five nurses and four focus group discussions in Osun State South West Nigeria Primary Health Care centres.

Results: Primary Health Care (PHC) nurses perceived and described patient-centered care (PCC) as a global approach to improve and enhance nursing care to foster patient participation. The narratives were categorised into two: positive and negative perception. Ten main themes emerged: (I) Attitude of the nurses (ii) Lack of enforcement and implementation, (iii) Experience of the nurses, (iv) Quality-Caring, (v) Effective communication with patient, (vi) Motivated and Proactive healthcare, (vii) Sharpen the form of care, (viii) Outcome and after-effect driven healthcare, (ix) Approved support, and (x) Guarantor of service and motivation.

Conclusion: Our participatory action research study on the assessment of nurses' perception on the utilization of PCC at the PHC for effective and quality healthcare service revealed the importance of nurses' role, acceptability of PCC and current nursing care practice at the Primary Health Care (PHC) rural community setting. Nurses as healthcare providers expressed PCC as a common and global approach that would enhance patient experiences and improves the quality of nursing healthcare delivery through integration of PCC and healthcare service at the PHC healthcare system.

Keywords: Patient-centered care, Perception, Nurses, Primary Health Care, Nursing care, and Healthcare services

\section{Introduction and Background}

Patient centered care (PCC) in public health environment is not a new concept. However, it is one of the creative approaches to improving planning, delivery and evaluation of health care services. PCC is based on the principle of mutual benefit for all partners in healthcare provision and patients. It targets all age groups in the healthcare environment and at any stage of any organization offering healthcare (Abraham \& Moretz, 2012; Leape et al., 2009). PCC's benefits over other primary healthcare approaches include dignity and respect, information sharing, and participation (Johnson et al., 2008). These benefits are key to achieving PCC according to Ellis 2012 since they allow the patient's voice to be heard from the start of the healthcare service.

PCC principle was proposed by the Children's Healthcare Association around 1987 in recognition of the role patients play in their own healthcare. This principle, however, has not been implemented at all levels in the healthcare system, healthcare institutions and organisations (Abraham \& Moretz, 2012). While individual nursing units may integrate PCC into the healthcare system, institutionally there is still a high level of resistance to its implementation at an institutional level. In addition, there are outdated policies in many healthcare centres that may hinder significant PCC practice in order to stay active, in particular the collaborative role of patients and their families in PCC (Dingeman, Mitchell, Meyer, \& Curley, 2007). 
PCC enhances the literacy levels in healthcare by motivating members of the community to participate in their own healthcare. This has been confirmed to result into positive outcomes such as reduction in malpractice complaints, improved health providers satisfaction, consultation time, patients emotional state and medication adherence (R. M. Epstein, 2000; Oates, Weston, \& Jordan, 2000; M. Stewart, 2003).

Organizations that have been successful in implementing and practicing PCC have recognized that while the path towards PCC may be challenging, it yields tremendous results not only for patients but also for staff members as reported in (Ahmann, Abraham, \& Johnson, 2010; Conway et al., 2006). Nurses play a main role in championing improvements like PCC in the health care system. This is because they are the well-placed professional group in their individual units and health organisations and management structures to champion the implementation and practice of PCC through advanced skill, knowledge and competencies (Kamei et al., 2017). They have also to transform the traditional scope of nursing practice and the institutional frameworks in addition to care in new fields of nursing profession. This in turn contributes to universal health coverage (UHC) according to (Evans \& Pablos-Méndez, 2016).

Additionally, PCC enhances patient empowerment and satisfaction as well as a reduction in the symptom severity, prudent use of healthcare resources and healthcare costs (Little et al., 2001). This collaborative initiative thus allows nurses and other healthcare providers to assist community members make healthcare decisions in partnership with the nurses (Komatsu, 2008). This concept is made explicit in the context of community healthcare, which aims to optimize the autonomy of patient care by maintaining the patient at home, thus avoiding hospitalization in health institutions and organisations. (Brown, McWilliam, \& Ward-Griffin, 2006). However, some researchers such as (DiGioia III, Lorenz, Greenhouse, Bertoty, \& Rocks, 2010; Laschinger, 2010; Smith, Dewar, Pullin, \& Tocher, 2010) have contrary opinion to this principle for being vague and poorly conceptualized. Thus, the objective of the study is to provide outcomes from assessment of nurses' perceptions about patient-centered care and the current trends in Primary Health Care system in South West Nigeria.

\subsection{Trends in PCC, Historical Perspective on PCC}

PCC was developed in the 1950s by Carl R. Roger, an American humanist psychologist in what he referred as to client centered therapy (Rogers, 1946a, 1946b, 1952). Today PCC is widely acknowledged as a core value in medicine (Nuño, Coleman, Bengoa, \& Sauto, 2012; Wagner, Austin, \& Von Korff, 1996). This has resulted into positive outcomes that include a reduction in malpractice complaints, improved patients satisfaction, improved consultation time, patients emotional state and medication adherence (R. M. Epstein, 2000; Oates et al., 2000; M. Stewart, 2003). In addition, Newell \& Jordan (2015) reported that PCC is a basis and fundamental ethics in promoting quality healthcare. This is in the understanding that patients are fundamentally human, leading to the promotion of the concept of PCC even with personhood, but not without its complexity (J. E. Mezzich et al., 2014). However, the contextualised meaning of personhood is also affirmed by Ortega Y Gasset's dictum as, "I am I and my circumstance". This defines a person as a reflection of what is happening both inward and outward, and both are part of the person (Cassell, 2010; J. E. Mezzich et al., 2014; J. E. Mezzich, Snaedal, Van Weel, Botbol, \& Salloum, 2011; Van Staden, 2011).

Historically, the concept of PCC has been explored through theoretical proposal and practical approach since the earliest Geneva conference that follows a process that allow acquisition of experience concurrently (Botbol \& Lecic-Tosevski, 2013; J. E. Mezzich et al., 2011; J. E. Mezzich, Snaedal, Van Weel, \& Heath, 2010). In essence, experience is a crucial aspect of the identity and existence of any institution that connotes the value of delineating institutional journeys, evaluating and recognizing PCC development.

PCC concept is a comprehensive approach to healthcare delivery services (Christodoulou, 1987; Patwardhan, Warude, Pushpangadan, \& Bhatt, 2005). This innovative concept in policy and practice moving to a conceptual optimal routine clinical practice is pivotal (Lewin, Skea, Entwistle, Zwarenstein, \& Dick, 2001; A. Miles \& Mezzich, 2011; Scholl, Zill, Härter, \& Dirmaier, 2014; van Dulmen, McCormack, Eide, Skovdahl, \& Eide, 2017).

In developed countries such as United Kingdom, United State, Australia and Germany, PCC has been in paper through policy leading to this statement "liberating the NHS: No decision about me without me" (Department of Health, 2009, 2012). Although this trend of this concept is clear in research and theoretical conceptualization, it is however fuzzy, elusive and even poorly implemented (De Haes, 2006; Hobbs, 2009; van Dulmen, 2003). Since the inception of PCC, several studies such as (R. M. Epstein et al., 2005; Mead \& Bower, 2000, 2002; J. E. Mezzich et al., 2011; M. Stewart, 2003; M. A. Stewart, 1995) have been done to describe the various dimensions and models of PCC to show its importance in the healthcare system. Besides its importance, the challenges involved in realizing and practicing PCC because it has been taken for granted by healthcare providers and other stakeholders have been presented (McCormack, van Dulmen, Eide, Skovdahl, \& Eide, 2017). 
Implementation of PCC concept is a necessity in order to achieve a sustainable healthcare coverage for all in Nigeria where it has been accepted for incorporation into the healthcare system. This means that, it is feasible at the grassroots level of the healthcare system provided the stakeholders work in collaboration with the nurses in its implementation and practice.

\subsection{The Impact of Perception on PCC}

There has been a tremendous need for PCC globally since its identification by the Institute of medicine of United State of America National Academies of Science as the leading contributor and factor in the provision of quality PHC (World Health Organisation, 2007). PCC is aimed at understanding illness experiences from the patient's viewpoint. The International Alliance of Patients Organization (IAPO) declared that PCC as a service, is based on placing the patient at the centre and around the patient's needs (International Alliance of Patients' Organizations, 2007).

In professional nursing circles, PCC is perceived to be an awareness of the importance of patient healthcare culture, family and friend's involvement, incorporation of values of love and respect and communication in all facets of patient's care leading to accountability to the patient (Jardien-Baboo, van Rooyen, Ricks, \& Jordan, 2016; Lawal, Agbla, Bola-Lawal, Afolabi, \& Ihaji, 2018). In South Africa PCC is endorsed in the second amendment Act No 3 of 2003. This act states that all South African citizens have a right to effective quality healthcare free from harm (South Africa, 1997). The South African PCC is established on an eight point "Batho Pele" principle that introduces a concept to service delivery putting people first, and the stated values of public service in the republic of South Africa (South Africa, 1997).

The role of nurses in delivering PCC in public hospitals and other facilities has become an imperative study for researchers since it is necessary to evaluate the knowledge and understanding of the nurses. In the findings by Terry in (Terry, 2010), nurses were found to be enthusiastic about sharing their perceptions with regards to PCC and what they perceived it to encompass. It is interesting to note that the perception of humane treatment was evident from the nurses. The component of human emotional aspects such as psychological, social, spiritual and emotional aspects which greatly influence an individual's health were presented. For instance, the awareness of the patient's cultural background and how to integrate the culture of a patient into the management of a patient and treatment plan were seen to be associated with PCC.

Therefore, in order to effectively render PCC, the nurses have to demonstrate a cultural awareness (Matteliano \& Street, 2012). Culture is known to be multifaceted and dynamic making it an important subject for the health practitioner's especially nurses to understand for quality and effective healthcare service in the PHC (Chenowethm, Jeon, Goff, \& Burke, 2006; Hardy, 2009; Van Rooyen, Jordan, Brooker, \& Waugh, 2009). To improve healthcare outcomes in PCC model, there has to be a demonstrated aptitude for cultural competence (Australian Commission on Safety and Quality in Health Care, 2010). However, there are many challenges and barriers but none is more influential than institutional and cultural based on individual ethnocentrism (Blackman, 2011). This is responsible for the current socialization of young healthcare professionals leading to perpetuation of negative attitudes, stereo-type behaviour towards vulnerable and culturally diverse populations (Ramsden, 2002).

The involvement of the family in key patient's decisions is a vital component of PCC and has been evident in research findings (Delaney, 2018; Pelzang, 2010). The similarities and differences have been identified in order to define and describe the level of family involvement in delivering PCC. In a systematic review of nine different models and frameworks in which PCC was defined, family and friend's involvement was found to be $60 \%$. This indicates the significant role played by family involvement in rendering PCC (Mitchell, Chaboyer, Burmeister, \& Foster, 2009; Shaller, 2007). The values of love and respect for patients were seen as one of the aspects of PCC. This is seen as incorporating a holistic PCC when interacting with patients and family members. Dowling in (Dowling, 2004), suggests and reports that nurses perceive love in nursing as going beyond the traditional duty of patient care and the willingness and commitment to the good of a patient before themselves. (Kvåle \& Bondevik, 2008) found that treatment with love and respect among patients included aspects of listening and trusting in a patient. This lead to patients feeling valued and felt a sense of control of their healthcare process, thus helping in their recovery efforts. The display of these values of love, respect and dignity were seen as integral to PCC and were perceived so by the nurses.

One way of expressing perception is through verbal and non-verbal communication. Nurses should be aware of different methods of communication that should be adopted when handling patients. (Levinson, Lesser, \& Epstein, 2010) reports that communication skills form a fundamental component of PCC. Evidence has demonstrated the impact of PCC which include patient satisfaction, adherence to recommended treatment and management of chronic diseases (Arora, 2003; R. Epstein \& Street, 2007). However, (Robinson, Callister, Berry, \& Dearing, 2008) 
affirms that effective communication among healthcare practitioners, especially the nurses is related to PCC model effectiveness and practices as it lacks clear measurement tools to clearly show its effectiveness.

Dignity and compassion are being emphasized and driven by the growing concern within the nursing fraternity. This is because PHC has "lost their way" as its quality has been inconsistent across countries, regional divisions within countries and even globally (Maben \& Griffiths, 2008). The true meaning of compassionate care has been a subject of discussion and specifically on how its teaching and measurement can be done (Bradshaw, 2009; Papadopoulos \& Ali, 2016; Straughair, 2012). The key question is how do we teach nursing students and professional nurses compassion? Although compassion is included in the nursing curriculum, it is one component that is less prominent than the technical components in the nursing profession, as it lacks clear measurement tools to its effectiveness (Firth-Cozens \& Cornwell, 2009; Shea, Wynyard, West, \& Lionis, 2011).

Accountability is a key component in perception. Adamson \& Dewar (2011) stressed the importance and vitality of how for example nursing students should be supported to develop compassionate skills and knowledge in caring for patients. Incorporating compassionate skills in the training and work environment through in-service education can improve the PCC model. Moreover, nurses do not work in isolation within the healthcare system but with the support from other disciplines. There is need for inter-disciplinary collaborative team work. This collaborative drive is further encouraged by WHO framework for action on inter-professional education and collaborative practice as reported by (Gilbert, Yan, \& Hoffman, 2010). This is aimed at providing effective delivery of the PCC model in the healthcare system. Incorporation of multiple healthcare workers allows different healthcare professionals with different healthcare backgrounds to offer quality and comprehensive service by partnering with patients, their families and friends (Pelzang, Wood, \& Black, 2010).

\subsection{Cost Implication of PCC}

PCC's involvement in reducing PHC's total cost remains a topic of discussion. The reduction in healthcare costs remains unanswered, although there is increasing evidence of PCC's positive impact in achieving the triple Aims goals of population health through improved care experiences and lower healthcare costs (Gilfillan et al., 2010; Jackson et al., 2013; Daniel D Maeng et al., 2012; Daniel D Maeng et al., 2015; Paustian et al., 2014; Reid et al., 2010; Rosenthal et al., 2016; Rosenthal et al., 2013; van Hasselt, McCall, Keyes, Wensky, \& Smith, 2015). In fact, PCC may increase the cost of care, especially in the short-term as it greatly employs preventive care. However, this short-term increase in cost of care is offset by the large decrease in the cost of acute care which is linked to poor access to early PHC. In other words, PCC, therefore, focuses on the "upstream" in the whole care process. For instance, the PHC clinic visits, provision of preventive and comprehensive care and care coordination to reduce the "downstream", emergency department visits and acute hospitals admissions (Daniel D Maeng et al., 2015).

It is imperative to note that most research studies on cost implications of PCC tend to focus on value achieved from the implementation of PCC as a model in PHC. In addition, there are few studies on direct cost to delivery and implementation of PCC in relation to medical practice functions (Magill et al., 2015). However, from the reviewed literature there is no study that can conclusively provide proof of the efficacy of the PCC model in the healthcare system. As such, the available literature will provide a framework for understanding how best the PCC model can be implemented effectively in different environments and how it could be positively evaluated or measured.

A number of studies from the few studies on direct cost to delivery have found a reduction in downstream costs. For instance in emergency department visits relative to payments and shared savings (Reid et al., 2010). In 2009, (Zuckerman et al., 2009) did a study in which they compared practice cost per full-time equivalent (FTE) physician as a function level of PCC and PCC functioning. They found a minimum increment in the cost with high level non-PCC medical programs model implementation in their findings. Nevertheless, (Holtrop, Potworowski, Fitzpatrick, Kowalk, \& Green, 2015) examined personnel costs and revenue for care management only and concluded that reimbursement for a fee for service (FFS) has a $21 \%$ association with cost only. As such, the question of concern is what are the functional costs of running PCC, and how can they be assessed? (Daniel Dukjae Maeng, Sciandra, \& Tomcavage, 2016).

\subsection{Personnel Remuneration in PHC}

In Europe, the healthcare is individualized. Currently, a similar individualistic approach has taken root in the Nigerian healthcare as compared to a decade ago due to globalization (McCormack et al., 2017; J. Mezzich, Snaedal, van Weel, \& Heath, 2009).The impact of PCC in healthcare service delivery, has led to strategic changes in healthcare organisations. This is because PCC requires healthcare practitioners to acquire new knowledge and skills necessary for effective implementation (McCormack, Dewing, \& Mccance, 2011; J. E. Mezzich et al., 2011). As the current culture is evolving, the patients are beginning to realise their responsibilities thereby endorsing 
patient-centredness in the healthcare system. As a result, patients are treated as people who are capable of taking responsibilities for their own health thus advancing PCC concept drastically (McCormack et al., 2011; McCormack et al., 2017).

Incentives and compensation for the healthcare providers should also be introduced, reviewed and updated for effective quality integrated care outcome. The act of financial incentive will serve as a motivation for healthcare providers (Doran, Maurer, \& Ryan, 2017; Tsiachristas, 2016). Naturally, PCC in healthcare services will not emerge without a proactive change given the amount of challenges encountered by the designed approaches to achieve integration in the healthcare services. Hence, fundamental policies are vital to enable collaboration and support from the policy makers, professionals, community groups and service users to transform the healthcare and achieve an integrated PCC healthcare service (Santana et al., 2018).

\section{Methods}

\subsection{Study Design}

This study was a qualitative participatory action research design in which semi-structured interviews were employed. Thirty-five individual interviews and four focus group discussions were conducted among the nurses in the PHC that resulted into a sample size that was determined by the saturation levels of the data. This study was conducted in thirty different PHC centres that were selected purposively based on availability of registered nurses in Osun State, Southwest Nigeria. These PHC centres are at the grassroots level of the healthcare system located at the local government level with the aim of promoting health and wellness, prevention of ill-health and restoring good health in the communities.

The Federal Republic of Nigeria is divided into six geopolitical zones, namely: North-East, North-West, North-Central, South-East, South-West and South-South. Osun State, which is the main study environment is under South-West zone and has a population of 4,705,589 (National Population Commission and National Bureau of Statistics Estimates, 2016). A population of this size provides an adequate sample size for such a study.

The study adopted an interpretative data analysis approach as guided by Saldana and others (M. B. Miles, Huberman, Huberman, \& Huberman, 1994; Saldaña, 2015). Based on a guide by the research questions to obtain information from the participants through individual interviews and focus group discussion (FGD), participants' responses were transcribed verbatim. The transcripts were uploaded to NVivo 12 to organise the data. Relevant information was then coded from the participants' responses using content thematic analysis guide and the codes were categorised into two groups based on their similarities. These similarities were then used to develop the themes and subthemes of the study as guided in (Saldaña, 2015; Wicks, 2017).

\subsection{Ethical Consideration}

Humanities and Social Sciences Research Ethics Committee, University of KwaZulu-Natal with Protocol reference number: HSS/1772/018D, from all participants informed consent was obtained, and the research was conducted in line with Osun State PHC Board Research Ethic Committee (OSHREC) ethics.

\section{Results}

The purpose of this participatory action research is to explore the perception of nurses regarding utilization of PCC in provision of nursing healthcare services at selected PHC in Osun State Nigeria. One of the research questions in this study was: what are the perceptions of nurses on the implementation of PCC at the PHC setting in Osun State Nigeria? As such, thirty-five nurses were interviewed. Out of this number of participants, eight were males, twenty-seven were females and their ages were between 30 and 61 years. All the participants were registered nurses working in the PHC. A difference in perception by the nurses in the implementation of PCC in PHC in the community of Osun State Nigeria emerged in this study. As such, these different perceptions were categorized into positive and negative perception. In addition, the themes that emerged included: (i) Attitude of the nurses, (ii) Lack of enforcement and implementation, (iii) Experience of the nurses, (iv) Quality-Caring, (v) Effective communication with patient, (vi) Motivated and Proactive healthcare, (vii) Sharpen the form of care, (viii) Outcome and after-effect driven healthcare, (ix) Approved support, and (x) Guarantor of service and motivation. A summary of the categories, themes, sub-themes, evidences and their meanings are presented in Table 1 in the appendix.

\section{i) Attitude of the nurses}

From the theme Attitude of the nurses, two sub-themes were adopted based on the narratives of the participants as follows:

a) Sentiments of the Nurses 
Nurses expressed their sentiments that the priority of nursing care to patient should focus on the needs of the patient as a person defined by their individuality, own beliefs, desires, wants and needs. Even though the participants reported that they had heard about PCC integration into the PHC and that it was the most important practice in the community setting, they had neglected its practice. As a result, patients visited the traditional healers instead of seeking treatment at the clinics and health facilities. The extract below provides confirms this:

"Instead of coming to health centre they go to the traditional healer setting because they believe that they are religious that they care about their religion but if we now bring the approach into healthcare setting it will increase their flow (P03)".

"There are some believe they have that is affecting their health in a way... (FGD1, P07)."

b) Uncaring Attitude

Uncaring attitude was reported as a hurdle to effective implementation of PCC among professional nurses in the PHC setting. Poor attitude to PCC approach due to perceived tensions in the interactions with the patients and families were reported by the participants. This is well captured in the excerpts of one of the interviews:

"The way we treat our patient... some of us, the way we relate to our patient is not even the best (P11).

Some patient that they will come to us, to confide in us but when they tell us their secret immediately they left we will just be sharing their secret with others which is not supposed to be... (P05)".

\section{ii) Lack of enforcement and implementation}

In this theme, the following two sub-themes emerged: (i) low empowerment (ii) lack of commitment from the management.

a) Low empowerment

Participants reported on the need to increase the number of nurses as well as resources to drive the PCC implementation. This study identified low productivity and poor commitment towards PCC practice from both the nurses and the healthcare organizations due to low empowerment. As such, the quality of healthcare service provision to the community was negatively affected. This can be confirmed by the following excerpt:

"...due to some circumstance of our nation, it has not been totally implemented due to some circumstance in Nigeria, there is low empowerment in this service, there are different things (P15)"

b) Lack of commitment from the management

From the data acquired, the healthcare service providers acknowledged the importance of PCC concept in the provision of healthcare services. However, this concept had not been fully practiced in their setting. Quality and value-based healthcare services are determined by the healthcare practices. As such, the lack of enforcement and implementation indicates the nation's lack of interest to enhance the quality of healthcare service delivery to its people. The evidence below reveals this:

"There is no policy that is backing it up... so it has not been effective, not effectively carried out by all the health care practitioner in the facility (FGD4, P01)".

"I think having a guide will enable us to carry out this patient centered care effectively... (FGD, P05)."

\section{iii) Experience of the nurses}

In this theme, understanding practice and periodic training and skills education were the two sub-themes.

a) Understanding Practice

A good number of the participants revealed that understanding practice is an influencing factor to both the quality of healthcare services and PCC implementation. It was reported that knowledge in PCC is essential and fundamental to nursing care in the PHC. Unfortunately, the nurses either have little or no knowledge about PCC concept and its practice. The extracts below corroborate this:

"When you are knowledgeable it will affect the way you carry out procedure and the way you render care to patient based on the knowledge that you have gather (P21)."

"I will still encourage that we the nurses should learn more about our profession so that when we have this concept it will be easy for us to practice... The fundament knowledge of what it takes to practice it, we still need orientation (P03)."

b) Periodic Training and Skills Education 
Nurses reported the need for in-service training and skills upgrading education programs to empower them. Since this is a common strategy globally to enhance healthcare services, nurses and other healthcare professionals' education, skills and competencies in PCC is essential. There is need to recognise, develop and integrate PCC practice into the PHC healthcare system through periodic training and skills education. However, participants reported that they did not have sufficient skills and training on PCC. The quote below reflects this:

"There should be like a seminar or workshop to training us about this client centered care. We are not used to it (P07)."

"In fact, to beginning with if we are not orientated towards patient centered care even we nurse might not do it the way we ought to do it. But if we are all orientated, if we know and familiar with the component, the approaches then we can do something (P32)."

\section{iv) Quality-Caring}

It was found from this study that the value of nursing care is well demonstrated by quality-caring which should be evidence-based practice. Participants stated that the quality of healthcare services is reflected by the outcome of the patients since caring is what matters to the patients. The comments below exemplified this:

"I think from my point of view is an approach that will actual improve the quality of care if we are rendering it... the patient will perceive it and even the public... (P25)."

"It is very relevant as a nurse you have to determine as a nurse I want to practice patient-centered care (P10)."

\section{v) Effective communication with patient}

Participants indicated involving patients and partnering with them in decision making which is fundamental to providing PCC. Communication is only effective when it makes the patients to feel at ease with healthcare providers, reduce patients' anxiety, and build confidence in them. The following excerpts confirm this:

"I think this concept is an important issue we must know especially the way we relate to our patient; the way we express ourselves to them (P35)."

"We are closer to the people at the grassroots, if we can incorporate PCC it will have a long way to go...is going to improve the service we give to our client and it like contribute effectively to their health (FGD2, P02)."

"Taking care of patient or a client especially in primary health care center is not about the patient having a particular disease so patient centeredness is necessary (P31)."

\section{vi) Motivated and proactive healthcare}

In this study, motivated and proactive healthcare emerged as a theme and consist of two sub-themes based on the narrative of the participants:

a) Compel to do normal thing

Participants acknowledged and reported that PCC is an approach of doing normal things. PHC nurses expressed that PCC is essential and important in the PHC healthcare system. They further indicated that government should support and create programmes on integration of PCC strategies at the PHC health system. The quotes below confirm this:

"So, is going to make the work easier... using PCC during healthcare delivery will ease the pressure of nurses... It's going to make our job easier and the care gets interesting... (P02)."

"Nurses are in the front line, so nursing profession should be given a free hand in collaborating or working with this concept (P09)."

b) Acceptance of usefulness

Participants showed that they had learnt and accepted PCC as a good practice that will bring about harmony of action into the PHC healthcare system. However, they required motivation. PCC strategies are useful in caring for patients because they enable the healthcare professionals to shift the caring to be collaborative with the patient. This is reflected in the extracts below:

"It is a good strategy which should be implemented to make health care delivery appropriate for client. I think is a good concept (P013)."

"This will be great for the nurses and the community because both will benefit from it...It is very good if we can integrate it in the service, especially at the primary health care center (FGD3, P06)." 


\section{vii) Sharpen the form of care}

Two sub-themes emerged from the theme sharpen the form of care as follows:

a) Interpersonal relationship

Participants revealed that PCC concept enhanced interpersonal relationship which enriched and transformed the patients' experience and perception about nurses. This is because actions that are health related are also interrelated due to their significant functions on the patients and the community. The extracts below reflect this:

"I think it will be very helpful, it will tailor the way we interact with our patient (P11)."

"It has to do with mood and emotion you understand, I may be pleasant today maybe tomorrow for one reason or the other but if there is a define guide that you need to follow, it becomes more professional (P19)."

b) Effective communication and engagement

This sub-theme was reported to improve the quality of nursing care and provide a better way of engaging the rural community effectively for improved outcome as narrated by the participants. Community engagement is a central component of PHC priority program to ensure healthcare services are appropriately tailored to the community values and needs. The people get opportunity to be involved through an engagement role by considering their decisions in the healthcare process. The comments below exemplified this:

"I think this concept is an important issue we must know especially the way we relate to our patient, the way we express ourselves to them, the believe of the patient even the way we behave to our patient, how the patient will be treated, the care (FGD1, P03)"

"The patient will be able to open up to you and they will be able to report on time on whatever is happening to them (P04)"

\section{viii) Outcome and after-effect driven healthcare}

Two sub-themes were developed out of this theme and are discussed as follows:

a) Being public-spirit

Participants described their perceptions on PCC as a concept that could help the community to get better and quality healthcare services. They expressed awareness of quality healthcare which includes respect and value of patient, preference and attention to patient. The following excerpts aptly support this:

"Taking care of patient or a client especially in primary health care center, is not about the patient having a particular disease so patient centeredness is necessary... Our patients will benefit more from these services and will even enable them have trust in us (FGD2, P03)."

"It will be good to create more awareness to people generally, not really treating a particular illness...Actually it will help us to achieve health for all because there are a lot of benefit (FGD3, P05)."

"I like it if we can introduce it at the primary health care level because it will improve our work, it will reduce hospital stay (P27). “

b) Enrich and compliment nursing care

Participants revealed that providing care that is patient centered care would enrich nursing care. It would provide opportunity for the nurses to inform and involve patients on their own care, and respond effectively to the patients' needs. This confirms that nurses in PHC healthcare system perceive PCC integration and healthcare service delivery as a good approach in enhancing the quality of healthcare services. Participants further indicated that the value and role of PCC would be to enhance the time spent with the patients which will in turn improve the quality of care. The quotes below confirm this:

"These things are geared towards bringing about the health of individual client or patient which at least will help the community... It will help us to reduce this issue of maternal deaths due to pregnancy. Even the infants' mortality (P33)"

"When patient-centered care is use for patients it will make the patient to take adequate care of herself and it will reduce the time visiting the hospital... I think is going to be a step in the right direction (P06)."

"....when you plan with them base on the available resources they will be able to consent with what you plan with them thereby there will be positive outcome (P01)." 


\section{ix) Approved support}

This theme had only one sub-theme of increased information sharing with the patient.

a) Increase information sharing with the patient

In this study, it was reported that caring for individuals under PCC approach increased information sharing between nurses and patients. This provided an opportunity for the patient to be informed and share their personal preference. The extract below is a testimony to this:

"I think we need to improve...It will improve our nursing care and it will improve the community health. If PCC is been promoted it will improve the status of their health and our healthcare prevention will be improving...(P29).

"It will enhance our work, it will make it to be effective, and then it will prevent omission when there are rules and guide to follow (P12)."

\section{x) Guarantor of service and motivation}

Guarantor of service and motivation has the following sub-themes that emerged from the data:

a) Government commitment and support PCC

Participants revealed that lack of action from the government indicated that the government was yet to fully embrace this concept as a means to improving and driving the nation to sustainable healthcare coverage for all. Participants further reported on the need for the government to fully support and invest in the PCC concept especially at the PHC settings of the healthcare system. This was to be through initiation of quality assurance programs, ensuring adequate nurses to patient ratio in PHC facilities and organizing periodic training for healthcare providers. It was also observed that the problem in PHC healthcare system is not only in its implementation but also on its enforcement and quality assurance prioritization. In addition, participants also mentioned that the government should re-look into the cost of healthcare and find ways of reducing the cost burdens from the people in the community. As such, the government should commit itself by ensuring that healthcare providers at the grassroots level are well informed and motivated to utilize the PCC concept. This is reflected by the following statement:

"We still need encouragement from the stakeholders, the government because health is wealth if the community is healthy the State is healthy the nation will be healthy... and encourage health professionals (P08)."

"So I will say that it is a nice concept and it is something that will enhance good care if it is implemented, if it is formalize...It's should be compulsory in the primary health care center because there are other cadres (P17)."

"My own perception is it can work, when the government employs more qualified staff nurse (FGD3, P05)."

b) Optimal performance to meeting healthcare needs

This sub-theme emerged as participants reported that PCC strategies should be central in PHC healthcare system. This is because it promotes patients and nurse partnership, acknowledges patient value and promotes flexibility in healthcare services. The nurses revealed that imbalances existed between their nursing practice and the available healthcare delivery manuals at their health facilities. As a result of this imbalance, they expressed their readiness and willingness to implement the PCC concept as a holistic approach to engage and interact with patients and members of the community. Thus, a shift from the traditional authoritarian nursing care will be achieved since PCC acknowledges the beliefs and values of patients towards their wellbeing. This is well exemplified by the excerpts below:

“...what is the standard? How active has it been? And how effective has it been, maybe we need some measure about it...I know that client center care or patient centered care is form of health service which is collaborative that's geared towards the health of a particular person at a point in time, there is need for us to meet the health need of the people (FGD1, P04)."

"...it will reduce the workload and patient stress... at times we abandoned it, because it has not become a policy, and so it will enhance our activities, it will enhance optima performance (P18)."

\section{Discussion}

From the results of this study, it was found that a significant number of the participants had strong belief in the concept and practice of PCC which was consistent with previous studies done by other researchers in this area (Mead \& Bower, 2002; M. Stewart, 2003). The main contribution of this study is the incorporation of nurses as the key stakeholders in the current system of healthcare practice at the rural PHC. Also, the qualitative approach adopted in this study allowed for an in-depth extraction of information on PCC in PHC healthcare system. This 
study is aimed at improving the quality of healthcare service delivery at the PHC setting by exploring nurses' perception on PCC since they are the main custodians of PHC. However, the main problem was found to be the misconception by the healthcare providers who thought they were providing and practicing PCC in the PHC but in reality they were not practicing PCC. Some of the participants claimed to have been using the PCC approach but lacked the practical skills required for PCC practice. As such, they asked for training to empower and enable them implement at their PHC. Therefore, transforming PHC to improve healthcare services should be more patient-centeredness, a task that this study identified to be for the stakeholders and the guarantors. While it could be argued that there are existing policies on the implementation of PCC in Nigeria, it was evident that they were not being adhered to. This was due to the knowledge gaps, lack of enforcement, lack of implementation skills and uncaring attitude from the nurses and other PHC stakeholders. A good number of participants revealed that understanding practice is an influencing factor to PCC implementation and quality of healthcare service. Knowledge on PCC is essential and fundamental to nurses in the PHC. Yet, this knowledge and skill is lacking among the nurses. This findings is consistent with those found by the authors in (Oluwatolania \& Philip, 2010; Santana et al., 2018).

The commitment from government is significant for the implementation of PCC in the PHC. This commitment should be at the national and local levels to promote development of healthcare policies and provision of necessary resources to support healthcare providers and PHC facilities at the grassroots level. Part of the role of the government was found to include: regulation of healthcare services standard, ensuring quality care services, enforcement of health system activities and development of policies and strategic plans for the integration of PCC into the healthcare services. Such steps and involvement of the government would inevitably lead to a reduction of non-communicable and communicable diseases.

Quality caring is a value that was found to be scarce among the healthcare providers. It is vital to determine whether the quality of the healthcare services provided to the people was satisfactory or not based on the evidence-based practice measures compared to other countries around the world. Additionally, this would enable the nurses to understand patients' perspective, as well as their experiences regarding their illness and explore the patients concerns and ideas. However, the participants revealed that the existing ways of communication with the patients in PHC were not effective to encourage positive outcomes from patients. Even though nurses showed a lot of interest in promoting health and wellness, and prevention of further health complications, a number of factors hindered the treatment of patients who required healthcare services through the PCC approach that would allow them to make decisions about their health. When healthcare professionals practice PCC, they place the patient at the centre of their healthcare by involving them at all times, offer support to them to learn and understand their health, assist the patient to be independent, modifying care to suit patients' needs to achieve positive health outcomes, treat the patient with compassion, show respect and dignity, and communicate effectively with the patient. These findings were similar to those presented in (Berwick, 2009; Chassin \& Galvin, 1998; Duffy, 2008; Fix et al., 2018; Hashim, 2017).

A significant factor in patient satisfaction about care is communication. This is one way in which nurses and other healthcare providers make sense to the patient since communication is a two-way interactive process with two or more people (Fleischer, Berg, Zimmermann, Wüste, \& Behrens, 2009; Frampton \& Charmel, 2009). Effective communication was identified by the participants to be essential to PCC since it is important for the nurses to communicate to the patients about their healthcare issues. This should be done in ways that the patients could understand and be able to provide feedback. As such, both the patients and nurses were involved in information sharing that eventually led to decision-sharing as well. Therefore, effective communication plays a vital role in the provision of quality healthcare services which is one of the strategies in the provision of PCC. This makes accountability a personal responsibility that the healthcare professionals should embrace as a continuous service to themselves, to their patients, to the community and to the government. That is, the nurses should be held accountable for their actions (Department of Health, 2008; Smith et al., 2010).

Even though the participants indicated that they engaged with the community, it was observed that PCC approach was not use. As such, the community healthcare nurses need to learn and have a meaningful collaboration with the people in the community. This would improve nursing care performance, community experiences on healthcare, patient outcome and job satisfaction. Thus, quality improvement in healthcare would be promoted and encourage patients to utilize the healthcare facilities effectively. The healthcare providers would then design interventions based on the knowledge, skills, ability and willingness of the patient to manage their own health. The need to prioritise PCC integration into the PHC therefore becomes paramount because the relationship between nursing care and patient outcome is significant. The evidence that people are experiencing quality healthcare is the end-result of such good practices in the PHC sector. Healthcare services and integrated PCC allows healthcare 
providers to treat patients with empathy, provide emotional support, respect and value as continuity of care and comprehension of information to patients on self-care would be available. Patients are assisted to understand what is required of them when accurate and clear information is provided through effective partnership and collaboration. Thus, a shift from the traditional authoritarian nursing care will be achieved since PCC acknowledges the patient's beliefs and values towards their wellbeing. Therefore, reshaping PHC healthcare system with PCC strategies becomes fundamental to improving healthcare experiences to both the healthcare providers and the patients. This concept is essential to healthcare providers at the PHC setting for its endeavour to foster quality healthcare services and to enhance and improve nurse patient working collaboration. In addition, the ability to fully operationalize PCC in the PHC setting lies with both the government as a guarantor and nurses as stakeholders of this innovative approach in healthcare service provision. The government needs to implement and enforce practical oriented PCC especially at the PHC level of the healthcare system.

\section{Conclusion}

Based on the results of this study, periodic in-service training of the nurses and a model of translating the new skills and competencies into practice should be embraced in nursing training and practice in PHC. In addition, the government should support and invest on PCC integration at all levels of the healthcare system by creating an enabling environment through effective regulation schemes, monitoring and enforcement agencies. Governments should pay much attention to the dimension of care in nursing. This will enhance proper utilization of PCC in PHC through identification and provision of solutions to potential barriers that exist between the patients nurses and the system.

\subsection{Limitations of the Study}

Even though this study involved participation of community healthcare nurses in the PHC practice, it did not include participation from the other healthcare professionals and the patients' perceptions. As such, this pauses a limitation to the results obtained from this study. We therefore recommend further research studies that will include participation of other healthcare professionals and patients' perceptions.

\section{Acknowledgements}

The authors will like to acknowledge all the participants of this study for their participation. Research reported in this publication was supported by the Fogarty International Center (FIC), NIH Common Fund, Office of Strategic Coordination, Office of the Director (OD/OSC/CF/NIH), Office of AIDS Research, Office of the Director (OAR/NIH), National Institute of Mental Health (NIMH/NIH) of the National Institutes of Health under Award Number D43TW010131. The content is solely the responsibility of the authors and does not necessarily represent the official views of the National Institutes of Health.

\section{Competing Interests Statement}

The authors declare that there are no competing or potential conflicts of interest.

\section{References}

Abraham, M., \& Moretz, J. G. (2012). Implementing patient-and family-centered care: Part I-understanding the challenges. Pediatric Nursing, 38(1), 44-47.

Adamson, E., \& Dewar, B. (2011). Compassion in the nursing curriculum: Making it more explicit. Journal of Holistic Healthcare, 8(3), 42-55.

Ahmann, E., Abraham, M., \& Johnson, B. (2010). Institute for patient-and family-centered care. Emergency Medicine, 15, 109-111.

Arora, N. K. (2003). Interacting with cancer patients: The significance of physicians' communication behavior. Social science \& medicine, 57(5), 791-806. https://doi.org/10.1016/S0277-9536(02)00449-5

Australian Commission on Safety and Quality in Health Care. (2010). Patient-centred care: Improving quality and safety by focusing care on patients and consumers. Canberra: Biotext.

Berwick, D. M. (2009). What 'Patient-Centered'Should Mean: Confessions of an Extremist: A seasoned clinician and expert fears the loss of his humanity if he should become a patient. Health Affairs, 28(1), 555-565. https://doi.org/10.1377/hlthaff.28.4.w555

Blackman, R. (2011). Understanding culture in practice: Reflections of an Australian Indigenous nurse. Contemporary Nurse, 37(1), 31-34. https://doi.org/10.5172/conu.2011.37.1.031

Botbol, M., \& Lecic-Tosevski, D. (2013). Person-Centred Medicine and Subjectivity Interdisciplinary 
Applications of the Person-Centered Approach (pp. 73-79). New York, NY: Springer. https://doi.org/10.1007/978-1-4614-7144-8_8

Bradshaw, A. (2009). Measuring nursing care and compassion: The McDonaldised nurse? Journal of Medical Ethics, 35(8), 465-468. https://doi.org/10.1136/jme.2008.028530

Brown, D., McWilliam, C., \& Ward-Griffin, C. (2006). Client-centred empowering partnering in nursing. Journal of advanced nursing, 53(2), 160-168. https://doi.org/10.1111/j.1365-2648.2006.03711.x

Cassell, E. J. (2010). The person in medicine. International Journal of Integrated Care, 10(5), 50-51. https://doi.org/10.5334/ijic.489

Chassin, M. R., \& Galvin, R. W. (1998). The urgent need to improve health care quality: Institute of Medicine National Roundtable on Health Care Quality. JAMA, 280(11), 1000-1005. https://doi.org/10.1001/jama.280.11.1000

Chenowethm, L., Jeon, Y. H., Goff, M., \& Burke, C. (2006). Cultural competency and nursing care: An Australian perspective. International Nursing Review, 53(1), 34-40. https://doi.org/10.1111/j.1466-7657.2006.00441.x

Christodoulou, G. N. (1987). Psychosomatic Medicine (ed ed.). New York: Plenum Press. https://doi.org/10.1007/978-1-4684-5454-3

Conway, J., Johnson, B., Edgman-Levitan, S., Schlucter, J., Ford, D., Sodomka, P., \& Simmons, L. (2006). Institute for Patient-And Family-Centered Care.

De Haes, H. (2006). Dilemmas in patient centeredness and shared decision making: A case for vulnerability. Patient Education and Counseling, 62(3), 291-298. https://doi.org/10.1016/j.pec.2006.06.012

Delaney, L. J. (2018). Patient-centred care as an approach to improving health care in Australia. Collegian, 25(1), 119-123. https://doi.org/10.1016/j.colegn.2017.02.005

Department of Health. (2008). High Quality Care for All - NHS Next Stage Review Final Report. London: Department of Health.

Department of Health. (2009). Putting people at the heart of care. Retrieved March, 11th, 2019, from https://webarchive.nationalarchives.gov.uk/20130123200554/http://www.dh.gov.uk/en/Publicationsandstatis tics/Publications/PublicationsPolicyAndGuidance/DH_106038

Department of Health. (2012). Liberating the NHS: No decision about me, without me. London: Department of Health.

DiGioia III, A., Lorenz, H., Greenhouse, P. K., Bertoty, D. A., \& Rocks, S. D. (2010). A patient-centered model to improve metrics without cost increase: Viewing all care through the eyes of patients and families. Journal of Nursing Administration, 40(12), 540-546. https://doi.org/10.1097/NNA.0b013e3181fc1

Dingeman, R. S., Mitchell, E. A., Meyer, E. C., \& Curley, M. A. (2007). Parent presence during complex invasive procedures and cardiopulmonary resuscitation: A systematic review of the literature. Pediatrics, 120(4), 842-854. https://doi.org/10.1542/peds.2006-3706

Doran, T., Maurer, K. A., \& Ryan, A. M. (2017). Impact of provider incentives on quality and value of health care. Annual review of public health, 38, 449-465. https://doi.org/10.1146/annurev-publhealth-032315-021457

Dowling, M. (2004). Exploring the relationship between caring, love and intimacy in nursing. British journal of nursing, 13(21), 1289-1292. https://doi.org/10.12968/bjon.2004.13.21.17127

Duffy, J. R. (2008). Quality Caring in Nursing: Applying Theory to Clinical Practice, Education, and Leadership. New York, USA: Springer Publishing Company.

Epstein, R., \& Street, R. L. (2007). Patient-Centered Communication in Cancer Care: Promoting Healing and Reducing Suffering. USA: National Cancer Institute, US Department of Health and Human Services, National Institutes of Health Bethesda, MD.

Epstein, R. M. (2000). The science of patient-centered care. Journal of Family Practice, 49(9), 805-810.

Epstein, R. M., Franks, P., Fiscella, K., Shields, C. G., Meldrum, S. C., Kravitz, R. L., \& Duberstein, P. R. (2005). Measuring patient-centered communication in patient-physician consultations: Theoretical and practical issues. Social Science \& Medicine, 61(7), 1516-1528. https://doi.org/10.1016/j.socscimed.2005.02.001

Evans, T., \& Pablos-Méndez, A. (2016). Shaping of a new era for health financing. The Lancet, 387(10037), 2482-2484. https://doi.org/10.1016/S0140-6736(16)30238-0 
Firth-Cozens, J., \& Cornwell, J. (2009). Enabling compassionate care in acute hospital settings. London: The King's Fund.

Fix, G. M., VanDeusen Lukas, C., Bolton, R. E., Hill, J. N., Mueller, N., LaVela, S. L., \& Bokhour, B. G. (2018). Patient-centred care is a way of doing things: How healthcare employees conceptualize patient-centred care. Health Expectations, 21(1), 300-307. https://doi.org/10.1111/hex.12615

Fleischer, S., Berg, A., Zimmermann, M., Wüste, K., \& Behrens, J. (2009). Nurse-patient interaction and communication: A systematic literature review. Journal of Public Health, 17(5), 339-353. https://doi.org/10.1007/s10389-008-0238-1

Frampton, S. B., \& Charmel, P. A. (2009). Putting PatientsFfirst: Best Practices in Patient-Centered Care (2nd. ed. Vol. 38). Francisco, CA: John Wiley \& Sons.

Gilbert, J. H., Yan, J., \& Hoffman, S. J. (2010). A WHO report: Framework for action on interprofessional education and collaborative practice. Journal of Allied Health, 39(3), 196-197.

Gilfillan, R. J., Tomcavage, J., Rosenthal, M. B., Davis, D. E., Graham, J., Roy, J. A., . . Goldman, R. (2010). Value and the medical home: Effects of transformed primary care. The American journal of managed care, 16(8), 607-614.

Hardy, S., Titchen, A., McCormack, B., \& Manley, K. (Eds.). (2009). Revealing nursing expertise through practitioner inquiry. Wiley-Blackwell, Oxford.: John Wiley \& Sons.

Hashim, M. J. (2017). Patient-Centered Communication: Basic Skills. American family physician, 95(1), 29-34.

Hobbs, J. L. (2009). A dimensional analysis of patient-centered care. Nursing research, 58(1), 52-62. https://doi.org/10.1097/NNR.0b013e31818c3e79

Holtrop, J. S., Potworowski, G., Fitzpatrick, L., Kowalk, A., \& Green, L. A. (2015). Understanding effective care management implementation in primary care: A macrocognition perspective analysis. Implementation Science, 10(1), 122. https://doi.org/10.1186/s13012-015-0316-z

International Alliance of Patients' Organizations. (2007). What is Patient-centred care? London: IAPO.

Jackson, G. L., Powers, B. J., Chatterjee, R., Bettger, J. P., Kemper, A. R., Hasselblad, V., . . Kendrick, A. S. (2013). The patient-centered medical home: A systematic review. Annals of internal medicine, 158(3), 169-178. https://doi.org/10.7326/0003-4819-158-3-201302050-00579

Jardien-Baboo, S., van Rooyen, D., Ricks, E., \& Jordan, P. (2016). Perceptions of patient-centred care at public hospitals in Nelson Mandela Bay. health sa gesondheid, 21(1), 397-405. https://doi.org/10.1016/j.hsag.2016.05.002

Johnson, B., Abraham, M., Conway, J., Simmons, L., Edgman-Levitan, S., Sodomka, P., \& Ford, D. (2008). Partnering with patients and families to design a patient-and family-centered health care system. Institute for Patient-and Family-Centered Care and Institute for Healthcare Improvement.

Kamei, T., Takahashi, K., Omori, J., Arimori, N., Hishinuma, M., Asahara, K., . . Tashiro, J. (2017). Toward Advanced Nursing Practice along with People-Centered Care Partnership Model for Sustainable Universal Health Coverage and Universal Access to Health. Revista latino-americana de enfermagem, 25. https://doi.org/10.1590/1518-8345.1657.2839

Komatsu, H. (2008). Five years activities of St. Luke's College of Nursing 21st Century COE program: Creation of People-Centered Care. Japan Journal of Nursing Science, 5(2), 137-142. https://doi.org/10.1111/j.1742-7924.2008.00110.x

Kvåle, K., \& Bondevik, M. (2008). What is important for patient centred care? A qualitative study about the perceptions of patients with cancer. Scandinavian journal of caring sciences, 22(4), 582-589. https://doi.org/10.1111/j.1471-6712.2007.00579.x

Laschinger, S., Heather, K., Gilbert, Smith, S., Lesley, M., Leslie, K., (2010). Towards a comprehensive theory of nurse/patient empowerment: applying Kanter's empowerment theory to patient care. Journal of Nursing Management, 18(1), 4-13. https://doi.org/10.1111/j.1365-2834.2009.01046.x

Lawal, B. J., Agbla, S. C., Bola-Lawal, Q. N., Afolabi, M. O., \& Ihaji, E. (2018). Patients' Satisfaction with Care from Nigerian Federal Capital Territory's Public Secondary Hospitals: A Cross-Sectional Study. Journal of patient experience, 5(4), 250-257. https://doi.org/10.1177/2374373517752696

Leape, L., Berwick, D., Clancy, C., Conway, J., Gluck, P., Guest, J., .. O'Neill, P. (2009). Transforming healthcare: 
A safety imperative. BMJ Quality \& Safety, 18(6), 424-428. https://doi.org/10.1136/qshc.2009.036954

Levinson, W., Lesser, C. S., \& Epstein, R. M. (2010). Developing physician communication skills for patient-centered care. Health affairs, 29(7), 1310-1318. https://doi.org/10.1377/hlthaff.2009.0450

Lewin, S., Skea, Z., Entwistle, V. A., Zwarenstein, M., \& Dick, J. (2001). Interventions for providers to promote a patient-centred approach in clinical consultations. Cochrane database of systematic reviews, (4). https://doi.org/10.1002/14651858.CD003267

Little, P., Everitt, H., Williamson, I., Warner, G., Moore, M., Gould, C., . . Payne, S. (2001). Observational study of effect of patient centredness and positive approach on outcomes of general practice consultations. Bmj, 323(7318), 908-911. https://doi.org/10.1136/bmj.323.7318.908

Maben, J., \& Griffiths, P. D. (2008). Nurses in Society: starting the debate: National Nursing Research Unit at King's College London.

Maeng, D. D., Graham, J., Graf, T. R., Liberman, J. N., Dermes, N. B., Tomcavage, J., . . Steele, J. G. (2012). Reducing long-term cost by transforming primary care: Evidence from Geisinger's medical home model. The American journal of managed care, 18(3), 149-155.

Maeng, D. D., Khan, N., Tomcavage, J., Graf, T. R., Davis, D. E., \& Steele, G. D. (2015). Reduced acute inpatient care was largest savings component of Geisinger Health System's patient-centered medical home. Health Affairs, 34(4), 636-644. https://doi.org/10.1377/hlthaff.2014.0855

Maeng, D. D., Sciandra, J. P., \& Tomcavage, J. F. (2016). The impact of a regional patient-centered medical home initiative on cost of care among commercially insured population in the US. Risk management and healthcare policy, 9, 67-74. https://doi.org/10.2147/RMHP.S102826

Magill, M. K., Ehrenberger, D., Scammon, D. L., Day, J., Allen, T., Reall, A. J., . . Kim, J. (2015). The cost of sustaining a patient-centered medical home: experience from 2 states. The Annals of Family Medicine, 13(5), 429-435. https://doi.org/10.1370/afm. 1851

Matteliano, M. A., \& Street, D. (2012). Nurse practitioners' contributions to cultural competence in primary care settings. Journal of the American Academy of Nurse Practitioners, 24(7), 425-435. https://doi.org/10.1111/j.1745-7599.2012.00701.x

McCormack, B., Dewing, J., \& Mccance, T. (2011). Developing person-centred care: Addressing contextual challenges through practice development. The Online Journal on Issues in Nursing, 16(2), 1-11. https://doi.org 10.3912/OJIN.Vol16No02Man03

McCormack, B., van Dulmen, S., Eide, H., Skovdahl, K., \& Eide, T. (2017). Person-Centred Healthcare Research. UK: John Wiley \& Sons. https://doi.org/10.1002/9781119099635

Mead, N., \& Bower, P. (2000). Patient-centredness: A conceptual framework and review of the empirical literature. Social Science \& Medicine, 51(7), 1087-1110. https://doi.org/10.1016/S0277-9536(00)00098-8

Mead, N., \& Bower, P. (2002). Patient-centred consultations and outcomes in primary care: A review of the literature. Patient Education and Counseling, 48(1), 51-61. https://doi.org/10.1016/S0738-3991(02)00099-X

Mezzich, J., Snaedal, J., van Weel, C., \& Heath, I. (2009). The International Network for Person-centered Medicine: Background and first steps. World Medical Journal, 55(3), 104-107.

Mezzich, J. E., Appleyard, J., Botbol, M., Ghebrehiwet, T., Groves, J., Salloum, I., \& van Dulmen, S. (2014). Ethics in person centered medicine: Conceptual place and ongoing developments. International Journal of Person Centered Medicine, 3(4), 255-257. http://dx.doi.org/10.5750/ijpcm.v3i4.453

Mezzich, J. E., Snaedal, J., Van Weel, C., Botbol, M., \& Salloum, I. (2011). Introduction to person-centred medicine: From concepts to practice. Journal of evaluation in clinical practice, 17(2), 330-332. https://doi.org/10.1111/j.1365-2753.2010.01606.x

Mezzich, J. E., Snaedal, J., Van Weel, C., \& Heath, I. (2010). Introduction to conceptual explorations on person-centered medicine. International Journal of Integrated Care, 10(5), 1-2. dhttps://doi.org/10.5334/ijic.472

Miles, A., \& Mezzich, J. E. (2011). Person-centered medicine: Advancing methods, promoting implementation. International Journal of Person Centered Medicine, 1(3), 423-428. https://doi.org/10.5750/ijpcm.v1i3.95

Miles, M. B., Huberman, A. M., Huberman, M. A., \& Huberman, M. (1994). Qualitative Data Analysis: An Expanded ourcebook (2rd ed. ed.). London, UK: Sage. 
Mitchell, M., Chaboyer, W., Burmeister, E., \& Foster, M. (2009). Positive effects of a nursing intervention on family-centered care in adult critical care. American Journal of Critical Care, 18(6), 543-552. https://doi.org/10.4037/ajcc2009226

National Population Commission and National Bureau of Statistics Estimates. (2016). National Population Estimates. $\quad$ Retrieved 13th $\quad$ Oct $\quad 2019$, from https://africacheck.org/wp-content/uploads/2017/02/Population-Forecasts.pdf

Newell, S., \& Jordan, Z. (2015). The patient experience of patient-centered communication with nurses in the hospital setting: A qualitative systematic review protocol. JBI database of systematic reviews and implementation reports, 13(1), 76-87. https://doi.org/10.11124/jbisrir-2015-1072

Nuño, R., Coleman, K., Bengoa, R., \& Sauto, R. (2012). Integrated care for chronic conditions: the contribution of the ICCC Framework. Health policy, 105(1), 55-64. https://doi.org/10.1016/j.healthpol.2011.10.006

Oates, J., Weston, W. W., \& Jordan, J. (2000). The impact of patient-centered care on outcomes. Fam Pract, 49(9), 796-804.

Oluwatolania, B. O., \& Philip, A. (2010). Lack of integration in software systems for health practitioners in Nigeria: The way forward. Journal of Health Informatics in Developing Countries, 4(1), 47-51.

Papadopoulos, I., \& Ali, S. (2016). Measuring compassion in nurses and other healthcare professionals: An integrative review. Nurse education in practice, 16(1), 133-139. https://doi.org/10.1016/j.nepr.2015.08.001

Patwardhan, B., Warude, D., Pushpangadan, P., \& Bhatt, N. (2005). Ayurveda and traditional Chinese medicine: A comparative overview. Evidence-Based Complementary and Alternative Medicine, 2(4), 465-473. https://doi.org/10.1093/ecam/neh140

Paustian, M. L., Alexander, J. A., El Reda, D. K., Wise, C. G., Green, L. A., \& Fetters, M. D. (2014). Partial and incremental PCMH practice transformation: Implications for quality and costs. Health services research, 49(1), 52-74. https://doi.org/10.1111/1475-6773.12085

Pelzang, R. (2010). Time to learn: Understanding patient-centred care. British journal of nursing, 19(14), 912-917. https://doi.org/10.12968/bjon.2010.19.14.49050

Pelzang, R., Wood, B., \& Black, S. (2010). Nurses' understanding of patient-centred care in Bhutan. British journal of nursing, 19(3), 186-193. https://doi.org/10.12968/bjon.2010.19.3.46541

Ramsden, I. (2002). Cultural safety and nursing education in Aotearoa and Te Waipounamu. Victoria University of Wellington New Zealand.

Reid, R. J., Coleman, K., Johnson, E. A., Fishman, P. A., Hsu, C., Soman, M. P., . . Larson, E. B. (2010). The group health medical home at year two: Cost savings, higher patient satisfaction, and less burnout for providers. Health affairs, 29(5), 835-843. https://doi.org/10.1377/hlthaff.2010.0158

Robinson, J. H., Callister, L. C., Berry, J. A., \& Dearing, K. A. (2008). Patient - centered care and adherence: Definitions and applications to improve outcomes. Journal of the American Academy of Nurse Practitioners, 20(12), 600-607. https://doi.org/10.1111/j.1745-7599.2008.00360.x

Rogers, C. R. (1946a). Psychometric tests and client-centered counseling. Educational and Psychological Measurement, 6(1), 139-144. https://doi.org/10.1177/001316444600600112

Rogers, C. R. (1946b). Significant aspects of client-centered therapy. American psychologist, 1(10), $415-422$. https://doi.org/10.1037/h0060866

Rogers, C. R. (1952). "Client-Centered" Psychotherapy. Scientific American, 187(5), 66-75. https://doi.org/10.1038/scientificamerican1152-66

Rosenthal, M. B., Alidina, S., Friedberg, M. W., Singer, S. J., Eastman, D., Li, Z., \& Schneider, E. C. (2016). A difference-in-difference analysis of changes in quality, utilization and cost following the Colorado multi-payer patient-centered medical home pilot. Journal of general internal medicine, 31(3), 289-296. https://doi.org/10.1007/s11606-015-3521-1

Rosenthal, M. B., Friedberg, M. W., Singer, S. J., Eastman, D., Li, Z., \& Schneider, E. C. (2013). Effect of a multipayer patient-centered medical home on health care utilization and quality: The Rhode Island chronic care sustainability initiative pilot program. JAMA internal medicine, 173(20), 1907-1913. https://doi.org/10.1001/jamainternmed.2013.10063

Saldaña, J. (2015). The Coding Manual for Qualitative Researchers (3rd ed. ed.). Washington DC, USA: Sage. 
Santana, M. J., Manalili, K., Jolley, R. J., Zelinsky, S., Quan, H., \& Lu, M. (2018). How to practice person-centred care: A conceptual framework. Health Expectations, 21(2), 429-440. https://doi.org/10.1111/hex.12640

Scholl, I., Zill, J. M., Härter, M., \& Dirmaier, J. (2014). An integrative model of patient-centeredness-a systematic review and concept analysis. PloS one, 9(9), 1-9. https://doi.org/10.1371/journal.pone.0107828

Shaller, D. (2007). Patient-Centered Care: What Does It Take? New York: Commonwealth Fund New York.

Shea, S., Wynyard, R., West, E., \& Lionis, C. (2011). Reaching a consensus in defining and moving forward with the science and art of compassion in healthcare. Journal of Holistic Healthcare, 8(3).

Smith, S., Dewar, B., Pullin, S., \& Tocher, R. (2010). Relationship centred outcomes focused on compassionate care for older people within in - patient care settings. International Journal of Older People Nursing, 5(2), 128-136. https://doi.org/10.1111/j.1748-3743.2010.00224.x

South Africa. (1997). White paper on transforming public service delivery (Batho Pele White Paper). Pretoria: Government Printer

Stewart, M. (2003). Patient-Centered Medicine: Transforming the Clinical Method (3rd ed ed.). London, UK: Radcliffe Publishing.

Stewart, M. A. (1995). Effective physician-patient communication and health outcomes: A review. CMAJ: Canadian Medical Association Journal, 152(9), 1423-1433.

Straughair, C. (2012). Exploring compassion: implications for contemporary nursing. Part 1. British Journal of Nursing, 21(3), 160-164. https://doi.org/10.12968/bjon.2012.21.3.160

Terry, M. J. (2010). The Impact of Patient-Centered Narrative Interviewing on the Perceptions of Primary Care Clinicians: a Pilot Evaluation.

Tsiachristas, A. (2016). Financial incentives to stimulate integration of care. International Journal of Integrated Care, 16(4), 1-4. https://doi.org/10.5334/ijic.2532

van Dulmen, S. (2003). Patient-centredness. Patient Education and Counseling, 3(51), 195-196. https://doi.org/10.1016/S0738-3991(03)00039-9

van Dulmen, S., McCormack, B., Eide, T., Skovdahl, K., \& Eide, H. (2017). 18 Future Directions for Person-Centred Healthcare Research. Person-Centred Healthcare Research, 209. https://doi.org/10.1002/9781119099635.ch18

van Hasselt, M., McCall, N., Keyes, V., Wensky, S. G., \& Smith, K. W. (2015). Total cost of care lower among medicare fee - for - service beneficiaries receiving care from patient - centered medical homes. Health services research, 50(1), 253-272. https://doi.org/10.1111/1475-6773.12217

Van Rooyen, D., Jordan, P., Brooker, C., \& Waugh, A. (2009). Foundations of nursing practice (African edition): Edinburg: Elsevier.

Van Staden, W. (2011). Developing World's Perspectives on Ethics and Person-centered Care. International Journal of Person-centered Medicine, 1, 14-17. https://doi.org/10.5750/ijpcm.v1i1.15

Wagner, E. H., Austin, B. T., \& Von Korff, M. (1996). Organizing care for patients with chronic illness. The Milbank Quarterly, 511-544. https://doi.org/10.2307/3350391

Wicks, D. (2017). The coding manual for qualitative researchers. Qualitative Research in Organizations and Management: An International Journal, 12(2), 169-170. https://doi.org/10.1108/QROM-08-2016-1408

World Health Organisation. (2007). People centred heath care. A policy framework. Geneva: WHO Press.

Zuckerman, S., Merrell, K., Berenson, R., Gans, D., Underwood, W., Williams, A., . . Hammons, T. (2009). Incremental cost estimates for the patient-centered medical home. New York, NY: The Commonwealth Fund, October. 


\section{Appendix}

Table 1. Summary of the findings: themes, sub-themes, and evidences

\begin{tabular}{|c|c|c|}
\hline Themes & Evidences & Sub-themes \\
\hline \multirow{3}{*}{ Attitude of the nurses } & $\begin{array}{l}\text { Instead of coming to health centre they go to the traditional } \\
\text { healer setting because they believe that they are religious that } \\
\text { they care about their religion but if we now bring the approach } \\
\text { into healthcare setting it will increase their flow. }\end{array}$ & Sentiments of Nurses \\
\hline & $\begin{array}{l}\text { The way we treat our patient... some of us, the way we relate to } \\
\text { our patient is not even the best }\end{array}$ & Uncaring attitude \\
\hline & $\begin{array}{l}\text { Some patient that they will come to us, to confide in us but when } \\
\text { they tell us their secret immediately they left we will just be } \\
\text { sharing their secret with others which is not supposed to be. }\end{array}$ & \\
\hline
\end{tabular}

...due to some circumstance of our nation, it has not been totally implemented due to some circumstance in Nigeria, there is low

Lack of enforcement and empowerment in this service, there is different things like that...

implementation

There is no policy that is backing it up... so it has not been effective, not effectively carried out by the entire healthcare practitioner in the facility.
Low empowerment

Lack of managerial commitment
The fundament knowledge of what it takes to practice it, but we still need orientation...

When you are knowledgeable it will affect the way you carry out Experience of the nurses procedure and the way you render care to patient based on the knowledge that you have gather

There should be like a seminar or workshop to training us about this patient centered care. We are not used to it

\section{Understanding Practice}

Periodic Training and Skills Education

Quality-Caring

I think from my point of view is an approach that will actual improve the quality of care if we are rendering it...the patient will perceive it and even the public...

\section{Effective}

Communication with patients
I think this concept is an important issue we must know

especially the way we relate to our patient; the way we express ourselves to them
Motivated and Proactive healthcare service
It's going to make our job easier and the care gets interesting...

Compel to do normal thing

So, is going to make the work easier...using PCC during healthcare delivery will ease the pressure of nurses
This will be great for the nurses and the community because both of them will benefit from it

It is very good if we can integrate it in the service, especially at the primary health care center.
Acceptance of Usefulness 


Ithink we need to improve...It will improve our nursing care and
At will improve the community health. If PCC is been promoted it
will improve the status of their health and our healthcare
prevention will be improving
I think it will be very helpful, it will tailor the way we interact
with our patient

Sharpen the form of care

Outcome and after-effect driven healthcare service

I think this concept is an important issue we must know especially the way we relate to our patient, the way we express ourselves to them, the believe of the patient even the way we behave to our patient, how the patient will be treated, the care.

Taking care of patient or a client especially in primary health care center, is not about the patient having a particular disease so patient centeredness is necessary... Our patients will benefit more from these services and will even enable them have trust in us.

I like it if we can introduce it at the primary health care level
Increase information sharing with the patient

Interpersonal relationship

Effective community engagement

Being Public- Spirited because it will improve our work, it will reduce hospital stay

It is good to introduce client centered care since primary health Enrich and compliment nursing care care is a first contact with this patient... It would enhance the practice of nursing

We still need encouragement from the stakeholders, the government because health is wealth if the community is healthy the State is healthy the nation will be healthy... and encourage

Government commitment and support PCC health professionals

Guarantor of service and motivation ...what is the standard? How active has it been? And how effective has it been, maybe we need some measure about it...I know that client centered care or patient centered care is form of health service which is collaborative that's geared towards the health of a particular
Optimal performance to Meet the health needs

\section{Instrument for the individual interview}

\begin{tabular}{|l|l|}
\hline Pseudo/Identification Code & \\
\hline Code for PHC center & \\
\hline
\end{tabular}

\section{Introduction}

Good morning/day! Thank you for agreeing to meet with me and share your views.

As you may know, the purpose of this interview is to help us understand the practices of patient-centered care and your experiences.

Kindly let me review some important considerations before we begin the interview. I am recording this interview to ease the analysis of this qualitative data. However, all responses will be kept highly confidential.

By signing the consent form, you confirm that you have consented to participate in this study and that the interview/focus group discussion can be audio recorded.

The researcher is interested in both negative and positive comments and often the more challenging and in-depth comments will be most helpful. 


\section{Icebreaking}

Can you kindly give me a short profile of yourself (Current position, how long you have joined the PHC, and your academic qualification)?

\section{Main Interview Questions}

1. No doubt, nursing profession has come a long way in Nigeria. From your experience, what has been the mode(s) of delivery of nursing healthcare services in PHC in Nigeria? Have there been changes? If yes, would like you share with me some of these changes?

2. Could you please describe your understanding on the concept of patient-centered? Are you using Patient-centered care as part of your healthcare delivery strategy? Please kindly elaborate: probing questions (Approach)

3. What is your perception on PCC in terms of what it is, quality of care, relevance, strength, weaknesses, and suitability for improving quality nursing healthcare services in Nigeria PHC?

4. Which of the strategies do you commonly use at the point of care with patients during healthcare service? Probe: why?

5. Probing: Do you have any suggestions or solutions to the situation described?

6. To what extent are nurses ready to implement the PCC approach solutions?

7. Are there contextual factors necessitating the adoption of PCC in PHC in Nigeria? If yes, can you shed more light on these factors?

8. What factor(s) do you foresee as hostile to the implementation and use of PCC for the nurses?

9. If we are to embark on developing an implementation model as a guide for nurses in PHC in Nigeria, what specific suggestion do you have, in terms of design, content, and implementation?

\section{Instrument for the FGD interview}

\section{Ice break}

\section{Good day! Thank you for agreeing to meet with me and share your views.}

As you may know, the purpose of this FGD is to help us understand our nursing care practices based on patient-centered care and your experiences.

Kindly let me review some important considerations before we begin the interview. The discussion will be audio recorded. This is to ease the analysis of this qualitative data. However, all responses will be kept highly confidential.

By signing the consent form, you confirm that you have consented to participate in this focus group discussion and it can be audio recorded. I will like each participant to take note of the following ground rules before we proceed in the discussion:

People have right to their opinion. Therefore, there is no right OR wrong answer in this discussion.

- Do not mention your name at any point throughout this discussion.

- Introduce yourself as the pseudo name you have been given

- Every opinion matter because at the end of the day is going to help us

- Nobody should quieten anyone during discussion period

- Do not shut anyone up when contributing to the discussion

- All phones should be on silence

- Everyone is encouraged to share his or her opinion.

\section{Introduction}

PCC is a concept that require healthcare professionals' understanding of each patient as a whole by taking time to really get to know the patient, their values and preference. This in turn helps the healthcare provider to improve the patients' quality of life. Patients desire to be treated with dignity and respect and to be seen as holistic persons, and not merely as a functional impairment. 
- PCC, we have all heard about it, I am not sure if we have ever used it. What is it all about?

- Are there possible benefits to using PCC strategies in the healthcare system?

- Do you think providing healthcare services to patients using PCC concept is practical in Nigeria PHC setting? Can nurses provide PCC?

- Supposing that all the challenges are taken care of, do you think it is possible to implement PCC?

- What do you think about implementation model on PCC for the nurses in PHC?

\section{Copyrights}

Copyright for this article is retained by the author(s), with first publication rights granted to the journal.

This is an open-access article distributed under the terms and conditions of the Creative Commons Attribution license (http://creativecommons.org/licenses/by/4.0/). 